\title{
69. Histological and Electron Microscopical Studies on Neoplasia Subcutaneously Occurring in Xenopus laevis
}

\author{
By Tsutomu Oinuma, ${ }^{*}$ Masumi Seki, ${ }^{* *}$ and Makoto Asashima***) \\ (Communicated by Kiyoshi Takewaki, M. J. A., Sept. 12, 1984)
}

In amphibians, tumors have been rarely reported..3),4),11) In this paper, we describe some histological and electron microscopical features of tumors occurring under the skin of the African clawed frog, Xenopus laevis.

Materials and methods. In the South African clawed frogs (Xenopus laevis), neoplasia dealt with in this paper were found among the specimens purchased from a dealer in Hamamatsu, Shizuoka Prefecture, Japan. The frogs bearing tumors had been kept in a pond by the dealer together with many other individuals for a long period. All of them were raised from eggs. Between May 1983 and April 1984, four individuals of about 20,000 frogs were found bearing tumors. One of them found in May 1983 was kept in a plastic aquarium $(24 \times 33 \times 10 \mathrm{~cm})$ in this laboratory for about nine months at $20^{\circ} \mathrm{C}$ until autopsy. The frog was fed swine liver and water was renewed weekly. After the diameter of the swelling was measured transcutaneously, the frog was anesthetized with MS222 (Sankyo, Co.). The skin over the swelling was removed with scissors for gross examination of the neoplasia. A part of the tumor was then cut off with scissors, fixed in Bouin's solution, embedded in paraffin, sectioned at $8 \mu \mathrm{m}$, stained with Delafield's hematoxylin and eosin, and observed with a light microscope. For electron microscopy, samples were fixed in a buffered solution (0.05 M phosphate buffer, $\mathrm{pH} 7.2)$ of $2.5 \%$ glutaraldehyde containing $2 \%$ paraformaldehyde and $0.1 \%$ picric acid,5) and embedded in Epon. Sections were stained with $2 \%$ uranil acetate and lead citrate and examined with a JEM-100C electronmicroscope. The three other frogs bearing tumors were processed in a similar manner soon after they reached the laboratory.

Results. The four frogs bearing tumors were females, each with a cloacal process, one of the characteristics of the female. The 889-16.

*) Department of Anatomy, Miyazaki Medical Univ., Kiyotake, Miyazaki

**) Department of Microbiology, Faculty of Medicine, Tsukuba Univ., Niihari-gun, Ibaraki 305.

***) Department of Biology, Yokohama City Univ., Seto 22-2, Kanazawa-ku, Yokohama 236. 
animals varied in size, the length between the tip of the head and the cloaca measuring from 7.5 to $10 \mathrm{~cm}$.

Gross observations: The first frog (10 cm in length) had an abnormal swelling on the dorsal side at the base of the left hindlimb. Initially, the tumor was $14 \mathrm{~mm}$ in diameter, hemispheric in form. While the frog was kept under observation for about nine months, the swelling increased in size, reaching $18 \mathrm{~mm}$ in diameter. When the skin covering the swelling was removed, it was found that a part of the neoplasia was necrotic, while the rest was largely composed of a hard mass of white cells showing several black spots. The in-

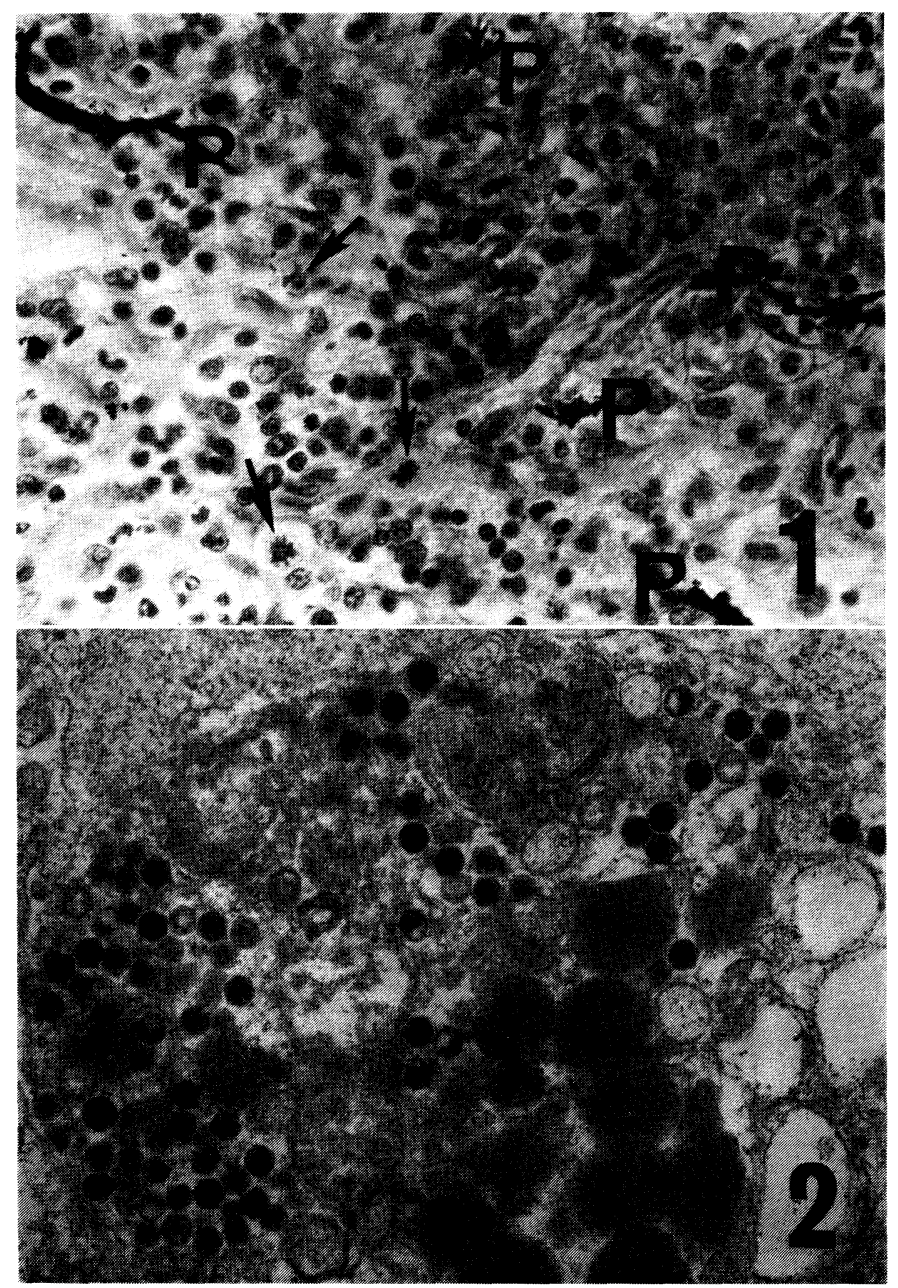

Figs. 1-2. 1: Section of Neoplasia. Mitotic figures (arrows) and melanine pigments $(\mathrm{P})$ are seen. $\times 210.2$ : Electron micrograph of viruslike particles in the tumor cell cytoplasm. Six-edged form of bodies is clearly seen. $\times 10000$. 
ternal organs and tissues, such as the digestive tract, liver, spleen, ovary and peritoneum, were normal in appearance.

In the second frog, a swelling was situated on the left dorsal region, posterior to the forelimb of the frog, $7.5 \mathrm{~cm}$ in length. The swelling measured $15 \mathrm{~mm}$ in diameter. Removal of the skin revealed that a part of the neoplasia was necrotic, while the rest consisted of a concrete cell mass. The outside appearance of the tumor was similar to the first one.

In the third frog, $7.5 \mathrm{~cm}$ in length, a swelling was found on the mid-dorsal region, posterior to the forelimb, measuring $18 \mathrm{~mm}$ in diameter. The fourth frog, $9.0 \mathrm{~cm}$ in length, had four swellings around the mid-dorsal region, posterior to the forelimb. The four swellings varied in diameter from 5 to $15 \mathrm{~mm}$.

Light microscopic observations: The tumors from the first and second frogs were subjected to histological studies. Each neoplasia had a necrosed portion, but the greater part consisted of clumps of relatively uniform cells. Cell components characteristic of the neoplasias were irregular-shaped melanophore-like cells and round cells with black pigment granules in the cytoplasm (Fig. 1). The nuclei of these cells were round or oval in shape. The cytoplasm was relatively abundant. In addition, some lymphoid cells, a few blood vessels and blood cells were encountered in the tumors. Mitotic figures were found occasionally (Fig. 1) (6 of 1,926 nuclei, $0.31 \%$ ). The two tumors showed no significant difference in histological structure.

Electron microscopic observations. In the cytoplasm of the tumor cells, virus-like particles were observed (Fig. 2). The particles, 6-edged in form, had a core and the surrounding membrane, ranging from 0.12 to $0.25 \mu \mathrm{m}$ in size, although the nature of the particles has not yet been thoroughly characterized. The virus-like bodies could not be found in the cytoplasm of the normal control skin and muscles.

Discussion. The neoplasias occurring spontaneously under the skin in four adult females of the clawed frogs (Xenopus laevis) were studied. The neoplasias were similar to each other both in site of occurrence and in form. Although it is not known whether the tumor was sex-related, frogs bearing the tumors were invariably females. One of the tumor-bearing individuals was kept under observation in the laboratory for a period of nine months. The tumor increased in outside diameter from 14 to $18 \mathrm{~mm}$ within the period. Two tumors were studied histologically. Although the tumors had a necrosed part, the greater part was composed of concrete masses of cells containing those with melanophore-like characteristics. Mitotic figures were found occasionally in the tumors. 
The neoplasias herein dealt with appear to be progressively growing melanophoma-like tumors. Melanophoma (or melanoma) is of rare occurrence in amphibians, ${ }^{6), 7), 10)}$ anurans in particular, and has never been reported from Xenopus.

Two frogs bearing tumors are still kept alive in the laboratory in oder to follow changes in diameters of the tumors. We are planning to determine whether the neoplasia in question is a melanophoma by the DOPA test and cell culture techniques.

Electron microscopic studies revealed virus-like particles in the cytoplasm of the tumor cells. Some other amphibian tumors such as Lucke' adenocarcinoma ${ }^{8), 9)}$ and Japanese newt papilloma ${ }^{1), 2)}$ have been known to contain viruses in tumor cells which are causative agents of the tumors. In Xenopus, this is the first report about virusbearing tumor cells. Further experiments such as isolation and transmission of particles are needed to determine the role of the virus in tumorigenesis.

Acknowledgements. We thank Dr. T. Ishikawa of the Cancer Institute, Tokyo, for his helpful advices. This work was supported in part by a Grant-in-Aid for Cancer Research from the Ministry of Education, Science and Culture, Japan.

\section{References}

1) Asashima, M. et al.: Cancer Res., 42, 3741-3746 (1982).

2) Asashima, M., and Oinuma, T.: J. Fac. Sci., Univ. Tokyo, sec. IV, 15, 151158 (1982).

3) Balls, M.: Cancer Res., 22, 1142-1154 (1962).

4) Balls, M., and Clothier, R. H.: Oncology, 29, 501-509 (1974).

5) Ito, S., and Karnovsky, M. J.: J. Cell Biol., 39, 168a-169a (1968).

6) Khudoley, V. V., and Mizgireuv, I. V.: Neoplasia, 27, 289-293 (1980).

7) Leone, V. G., and Zavanella, T.: Biology of Amphibian Tumors (ed. M. Mizell). Springer-Verlag, New York, pp. 184-194 (1969).

8) Mizell, M.: ibid. Springer-Verlag, New York, pp. 1-25 (1969).

9) Rafferty, K. A., Jr.: Cancer Res., 24, 169-185 (1964).

10) Rose, F. L., and Hershberger, J. C.: Science, 196, 315-317 (1977).

11) Schlumberger, H. G.: Cancer Res., 17, 823-832 (1957). 